\title{
Las canciones sefardíes y el ciclo de la vida. (Repertorio judeo-español de Oriente y Occidente)
}

Los judíos sefardíes han conservado, a través de generaciones, un rico patrimonio musical. Muchas de las canciones que componen este extenso repertorio musical tienen una ocasionalidad específica, estando ligadas a las ceremonias que marcan el ciclo de la vida humana, delineando su curso en sus tres principales fases: nacimiento, boda y muerte. Cada una de estas fases está marcada por ceremonias que, como rito de tránsito, definen al individuo y le integran en la vida de la comunidad. Las canciones que se cantan en las correspondientes ceremonias de circuncisión, boda y duelo constituyen el tema del presente estudio.

Como bien es sabido, tras su expulsión de España, los judíos se dispersaron por la cuenca del Mediterráneo formando nuevas comunidades, tanto en el Este, bajo los auspicios del imperio otomano (en lo que hoy son Turquía, Grecia, Yugoslavia y Bulgaria) como en el Oeste, donde se establecieron en diversas localidades del Norte de Marruecos. De ambas áreas llegaron los judíos eventualmente a Israel, y es de boca de tales inmigrantes de donde he recogido, en mis encuestas de campo en los últimos quince años, numerosas versiones de las canciones que integran el rico repertorio sefardí ${ }^{1}$.

\footnotetext{
1 Todos los ejemplos en el presente estudio son transcripciones de versiones que he recogido en mis encuestas de campo de los últimos quince años, cuyas grabaciones están conservadas y catalogadas en la Fonoteca Nacional en la Jewish National and University Library (jNUL), Universidad Hebrea de Jerusalén. En las transcripciones musicales se utilizan los signos $\sim$ sobre aquellas notas cuya longitud es algo mayor o menor, respectivamente, que la indicada en la notación, y los signos 1 I cuando la altura del sonido sobrepasa o desciende en menos de medio tono de la nota señalada. Las transcripciones de los textos están hechas de acuerdo al sistema utilizado por el Instituto Arias Montano, CSIC (Madrid), usando el español moderno con la adición de signos diacríticos para representar aquellos sonidos propios del judeo-español. Véase: lacob $\mathbf{M}$. HASSÁN, "Transcripción normalizada de textos judeo-españoles», Estudios Sefardíes, I (1978), 147-150.
} 
Todas las canciones presentadas aquí son cantadas en la lengua judeoespañola, sea en su tipo oriental (llamado también španiol, judezmo, y aún, erróneamente, ladino) o en el occidental (llamado bakitía). Respecto a este último debemos señalar que la dinámica de los procesos lingüísticos ha generado (con la conquista de Tetuán por los españoles -en 1860 - y luego con el protectorado español de 1912 a 1956) una rehispanización de la lengua de los judíos en Marruecos. Esta es la causa por la cual encontramos, entre los textos de las canciones marroquíes, algunos en hakitía, otros en español moderno y muchos en los cuales se alternan ambos.

El repertorio que nos ocupa es esencialmente vocal, cantado por solistas o en grupo. La mayoría de las canciones fue grabada de labios de mujeres, lo cual nos indica el lugar preponderante que la mujer sefardí ocupa en la ejecución, conservación y transmisión de la tradición oral judeo-española. Es más: hay ceremonias, como la del baño de la novia, en la cuales, lógicamente, sólo están presentes las mujeres y, por tanto, sólo ellas cantan las canciones pertinentes. En otras ocasiones, todo el público participa en la ejecución, pero, aún entonces, es frecuente que sea una mujer quien lleve el canto.

Mencionemos también que en las ceremonias festivas, como en las bodas, las canciones se acompañan con el tamborín - llamado sonaja en Marruecos y pandero (o panderico) en Oriente- y, eventualmente, con darbuqa y, en Marruecos, también con castañuelas.

Tal cumo corresponde al ciclo vital, comenzaremos por las canciones ligadas al nacimiento. La ceremonia que introduce al recién nacido, varón, en la sociedad judía es la circuncición que se celebra en la sinagoga y en la casa. El nacimiento de las niñas, si se celebra, es en forma muy modesta, sólo en familia.

Las canciones ejecutadas para la circuncisión se denominan «cantares o canticas de parida» (parida es el término que denomina a la madre de la criatura). A la parida se dirige el texto de nuestro primer ejemplo, grabado en Yaffo en 1975, cantado por Miriam Conforti, oriunda de Sofía?

2 En la ciudad de Yaffo se establecieron numerosos inmigrantes judios de Bulgaria, constituyendo una de las pocas localidades con una fuerte concentración de sefardíes de un mismo origen, lo cual contribuyó significativamente a la preservación de la tradición. 


\section{Ejemplo n. ${ }^{\circ} 1$}

\author{
Parida, El Dió voś guadre, \\ cuánto quiere la vuestra madre, \\ parida sos̀. \\ Cuando la comadre \\ dice: aide, aide, \\ arisponda la parida: \\ - Adonai me escapa. \\ Vino bollido, \\ bien arrevenido, \\ mos viva 'l parido, \\ también el nacido. \\ $S^{\prime}$ aqueja la parida \\ que no comió nada, \\ si coma la gallina, \\ los güesos al bib de la cama.
}

\author{
Alabar que mos escapó \\ a ver esta alegría, \\ que seiga un buen simán \\ y este nacido, \\ que yiva y el parido! \\ Ayolta, la parida, \\ di cara a la cocina, \\ y virés guisanderas \\ guisando comida. \\ Alabar... \\ Honrad a la sandaka \\ que todo ' 1 bien merece \\ le nació un hijo, \\ que el Dió se lo presente. \\ Alabar...
}

El texto tiene una estrofa introductoria de tres versos, de ellos dos largos (de 8 y 9 sílabas cada uno) y uno corto (de 5), cuyo contenido es la bendición de la parida. A esta estrofa sigue una construcción compleja: cuatro estrofas en dísticos monorrimos de versos largos (o cuartetas de rima a-b-a-b) y dos refranes, uno en cuarteta monorrima y el otro (que es el que se repite desde la segunda estrofa en adelante) de cinco versos (tres largos, de número de sílabas variable cada uno y dos cortos, de 6).

Después de la estrofa introductoria de bendición y alabanza a la parida, describe el texto el momento del parto: la comadre que dice «aide, aide» (que, para los búlgaros, equivale al español «dale, dale») y la parida que invoca a Adonai (Dios) para que la ayude a dar a luz.

En la siguiente estrofa, después de un breve refrán de alabanza al recién nacido y a su padre (el parido), se mencionan los cuidados que recibe la parida (que esconde los restos de su comida como precaución contra el mal de ojo).

El texto continúa con una especie de refrán (que luego se volverá a repetir) deseando que el nacido sea un buen simán, término hebreo (que, como otros muchos, es parte integral de la lengua judeo-española) que significa «señal», es decir, señal de buen augurio.

Las últimas dos estrofas, separadas siempre por el refrán, mencionan los preparativos para el festín con que se celebra la circuncisión y los honores acordados a la sandaka (la madrina). 

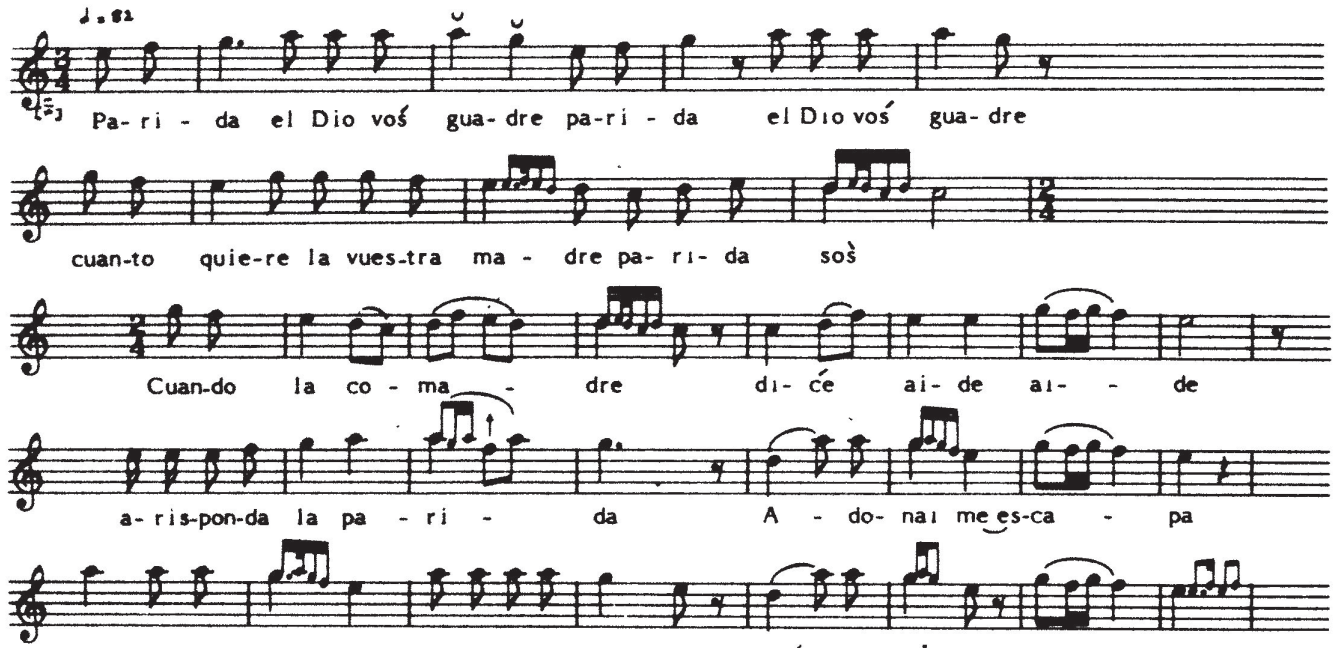

Vi- no bo - 111 - do biena-re-ve - $n i$ - do moś vi-va'l pa - ri - do
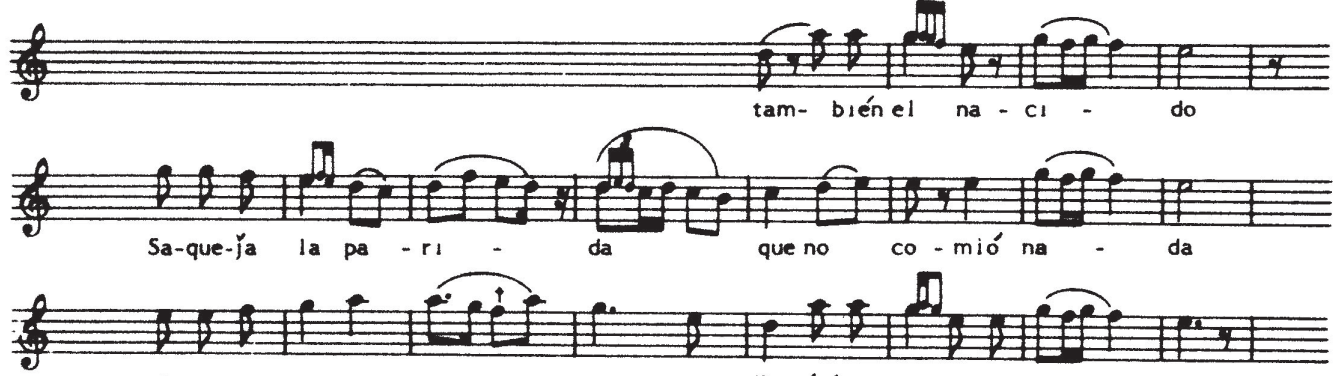

si co-ma la ga $-11 \mathrm{i}-$

na los güe-śćsal bib de la ca - ma

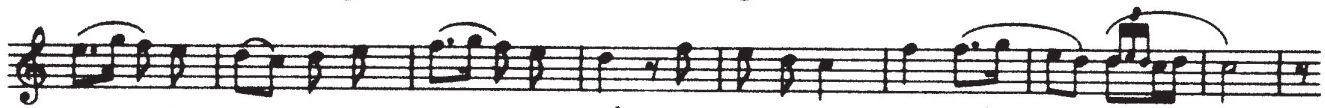

A - la- bar que mos es - ca- pó
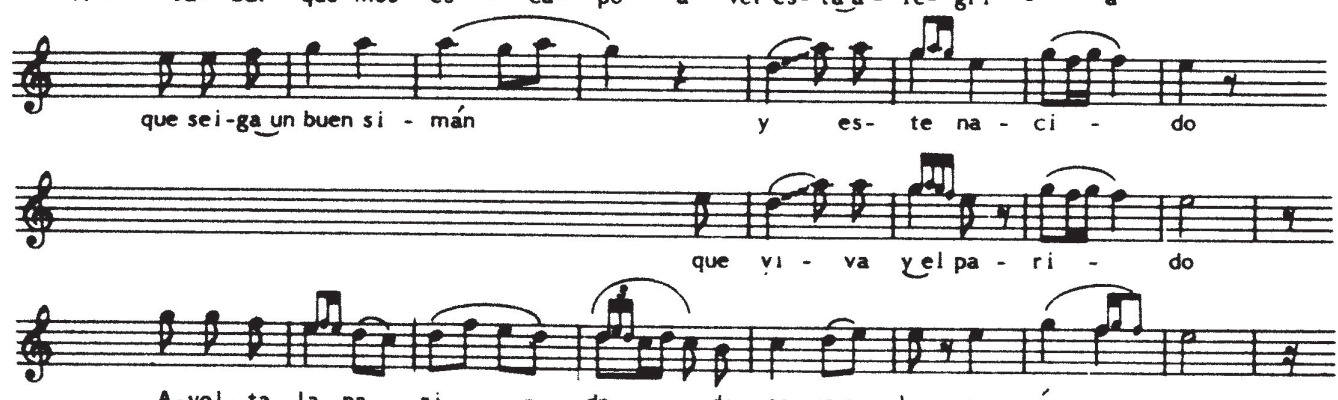

A-vol-ta la pa-ri da di ca-ra la co-ćı - na

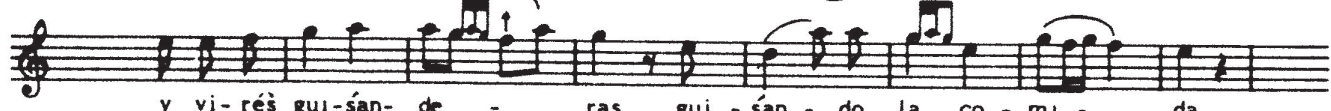

y vi-rés gui-san- de - ras gui - śan - do la co - mi - da

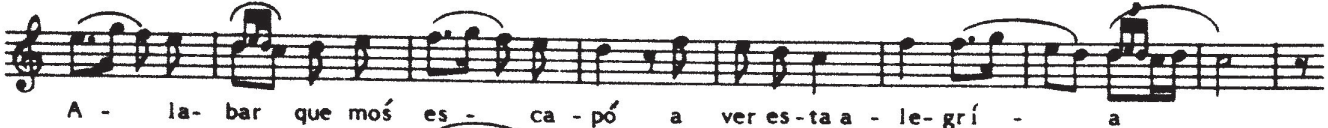

A - la - bar que moś es-ca - pó a veres-ta a - le-grí - a

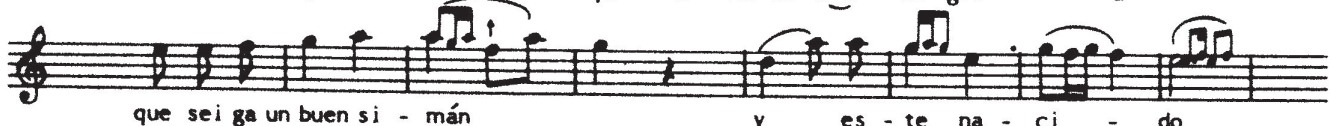

que sei ga un buen si - mán

12

tam- bién el pa - rl - do 
La música de esta canción tiene una estructura que aparece en otras canciones de esta región ${ }^{3}$ : una primera parte (la primera estrofa) distinta del resto, en melodía y ritmo, y no repetida después, que tiene un compás de $3 / 4$ y que viene seguida de otras estrofas musicales repetidas con variaciones, pero todas ellas en compás binario de $2 / 4$. La escala, en un diapasón de una séptima menor, está en el modo de Mi (semejando el maqam buzam), excepto en la primera estrofa, que está en Do (modo mayor). En esta primera estrofa la melodía se mueve mayormente dentro y alrededor de la tercera menor mi-sol, y sólo al final de la estrofa desciende al Do que define su modalidad.

Un mismo segmento musical finaliza todas las estrofas desde la segunda en adelante, así como los estribillos, diferenciando a estas unidades de la melodía de la primera estrofa. Este segmento musical comienza por la subfinalis en tiempo acentuado y por un salto ascendente a la quinta superior, concluyendo por un descenso a la tónica; las repeticiones de la melodía de este segmento se presentan, con diferente texto y con leves variaciones.

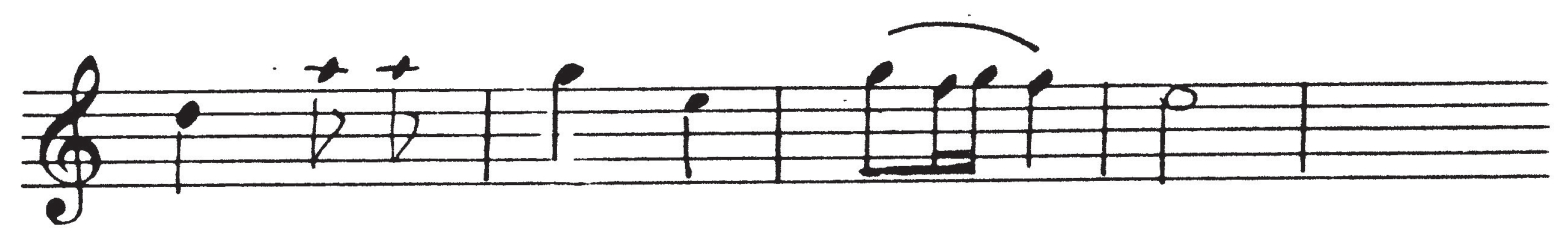

La melodía de esta canción es mayormente diatónica, moviéndose por sonidos conjuntos. El tempo es vivo, con tiempos y acentos claramente marcados. La relación texto/música es generalmente siläbica, con unas pocas ornamentaciones.

El ejemplo siguiente es una canción de circuncisión de Marruecos, grabada en Ashkelon en 1985 y cantada por Alicia Bendayán, de Tetuán.

El texto de la canción consta de diez versos octosilábicos, con rima asonante en $i$-o, en los primeros seis versos (excepto en el tercero, tal vez por error) y en $i-a$, en los cuatro restantes. Comienza por dirigirse al parido, a fin de despertarle para la circuncisión (para cercucir $=$ cir-

\footnotetext{
3 Este ordenamiento particular de las estrofas musicales, con una primera que difiere (en tonalidad, ritmo y marcha melódica) de todas las siguientes, ha sido apreciado en varias canciones de boda de los sefardíes búlgaros. Véase: Susana WEICH-SHAHAK, «Structural phenomena in the wedding songs of Bulgarian Sephardic Jews», Issachar BEN-AMI (ed.), The Sepharadi and Oriental Jewish Heritage Jerusalen: The Magness Press, The Hebrew University, 1982), pp. 413-420, en p. 416.
} 
cuncidar) de su hijo, con motivo de la cual ya se ha reunido el público (el kabal, en hebreo). Más adelante el texto comenta las gratificaciones que recibe la madre que ha dado a luz un varón, comparando la triste suerte de las que han tenido niñas.

También la melodía de esta canción tiene movimiento diatónico y es mayormente silábica pero, a diferencia de la anterior, su tempo es más calmo, sin división métrica y con una estructura formal basada en una sola unidad musical de dos frases, que se repite, con pequeñas variaciones, como una letanía, en los otros versos, llevando cada unidad dos versos del texto. Todas estas unidades musicales van encadenadas por sus finales no conclusivos (en el segundo grado de la escala), excepto la última, que termina en la tónica. La escala es hexatónica mayor con un diapasón de esa misma magnitud, comprendiendo el pentacordio do-sol, con el agregado de la subtónica si.

\section{Ejemplo n. 2}

Levantáivos, el parido, de este buen durce dormido, y el kahal está en la puerta para cercucir al niño. Las que pàrían los niños comíàn los buenos vicios, las que pàrían las niñas comíàn flacas sardinas, de la rabia que tenían peleàn con las vecinas.

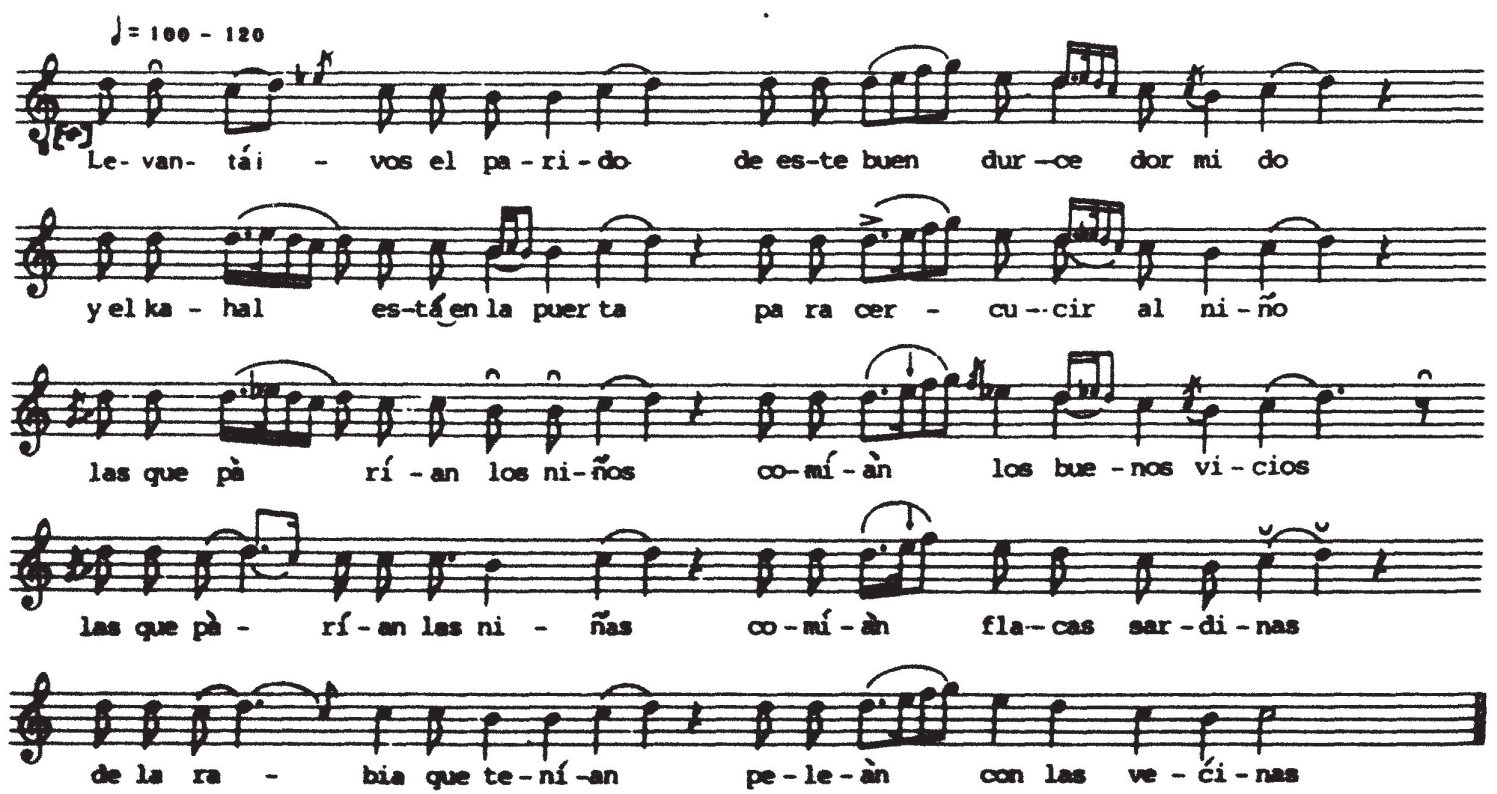


El siguiente rito de tránsito es el de la boda, ilustrado, tanto en Oriente como en Occidente, por gran cantidad de canciones. Podemos estipular, sin asomo de duda, que en el campo de las canciones con ocasionalidad fija, en todas las comunidades sefardíes, las de boda son las más numerosas. Esto se debe a la importancia del acontecimiento, pues la formación de una nueva pareja asegura la continuidad de la comunidad, pero, además, a que la boda comprende varias ceremonias específicas, cada una de las cuales tiene sus propias canciones. Tomaremos aquí tres de esas ceremonias, tal como se reflejan en los cantares de Oriente y Occidente.

La primera es el ajugar o ajuar, es decir, la exhibición del ajuar de la novia, celebrada por sus padres. En esta ocasión se muestran todos los artículos que constituyen el ajuar, extendidos sobre mesas y tendidos en cuerdas dispuestas para ese propósito. A la celebración se invita especialmente a la familia del novio, con el objeto de que puedan ver e inspeccionar si no falta nada.

Entre las canciones que se cantan en Oriente hemos escogido una versión grabada en Yaffo en 1977, cantada por Matilda Lazar (apodada «Mazal-tov» por ser popular en las bodas donde siempre cantara; su apodo, en hebreo, significa «buena suerte», y es el saludo y buen augurio para tales ocasiones), oriunda del pueblo Mustafa Pasha (Turquía), de donde pasó a Sofía (Bulgaria) ${ }^{4}$.

El texto de este ejemplo se refiere, en forma explícita, a la presentación del ajuar y a la novia que se va «a buen mazal», y tiene dos estrofas y un refrán o estribillo que se repite después de cada una de ellas. En cada estrofa hay tres versos: dos largos (de 8, 9 ó 10 sílabas) y un tercero corto (de 4) que es común a ambas estrofas. También el refrán, de dos versos, tiene uno largo (de 10 sílabas) y uno corto (de 4).

\title{
Ejemplo n. 3
}

\author{
Ajugar de novià galana \\ a buen mazal ya la mandan, \\ enbuenhora. \\ Enbuenhora se odrenó la boda, \\ ésta y otra.
}

\footnotetext{
4 Como en otros casos de movilidad de los sefardíes dentro del área en que vivían, la transición geográfica de la informante dificulta la definición del origen de sus canciones; interrogada al respecto no pudo asegurar qué canciones de su repertorio había aprendido en Turquía y cuáles en Bulgaria.
} 
Arrecavdí yo lo que quería, ajugar de novia janina, enbuenhora.

Enbuenhora se odrenó la boda, ésta y otra.
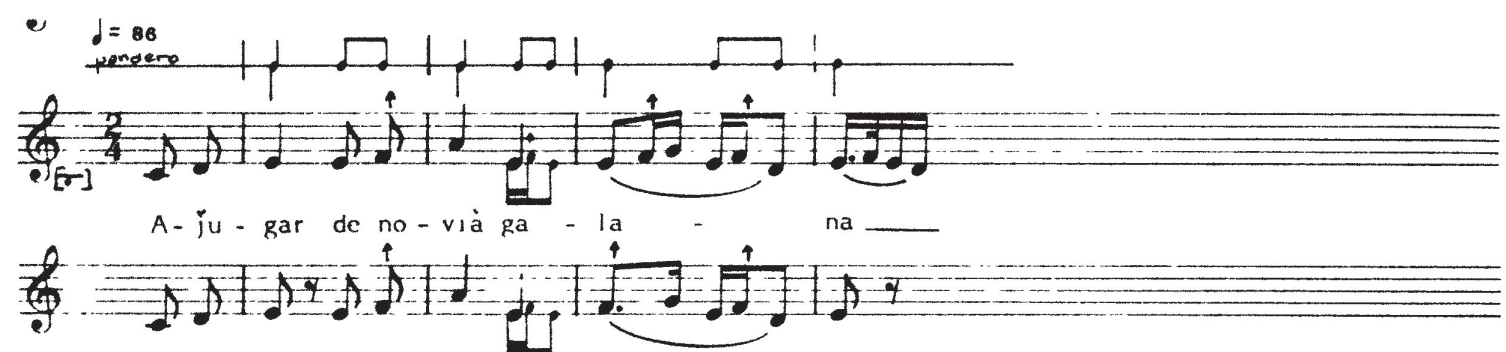
A- ju-gar de no - viàga - la na
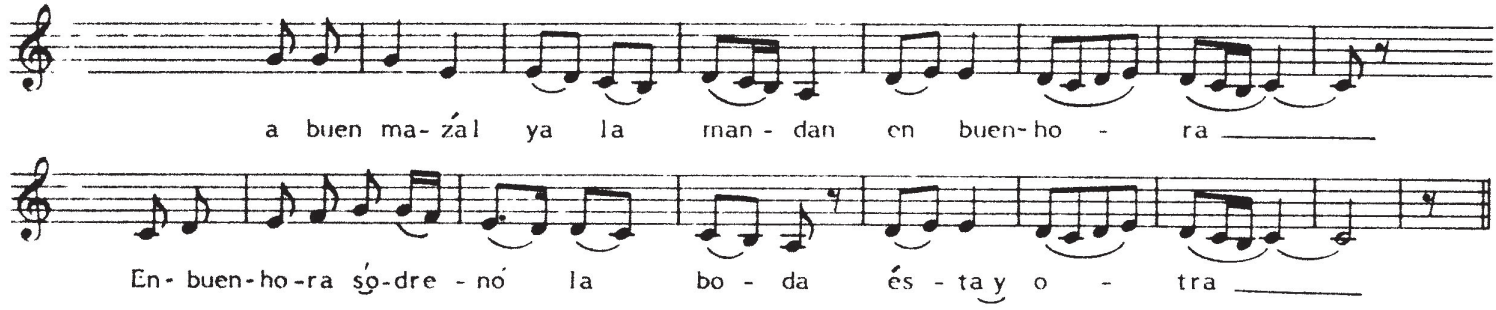

La estructura musical es paralela al texto, con un ritmo vivo, en compás binario (2/4). La escala es de tipo mayor, con el cuarto grado algo elevado (resultando casi en en $3 / 4$ tono entre el tercer y el cuarto grado del tetracordio), en un diapasón de una octava.

Nótese el descenso a la cuarta inferior (debajo de la tónica) en el compás n." 8, al final de la tercera frase, como anunciando la última que completará la estrofa musical; lo mismo sucede en la mitad del refrán (que es también su penúltima frase), lo cual constituye una característica que, tanto como la repetición de la primera frase de la canción, en música y texto, ha sido constatada en otras canciones funcionales de esta misma región 5 .

en la 2afrase

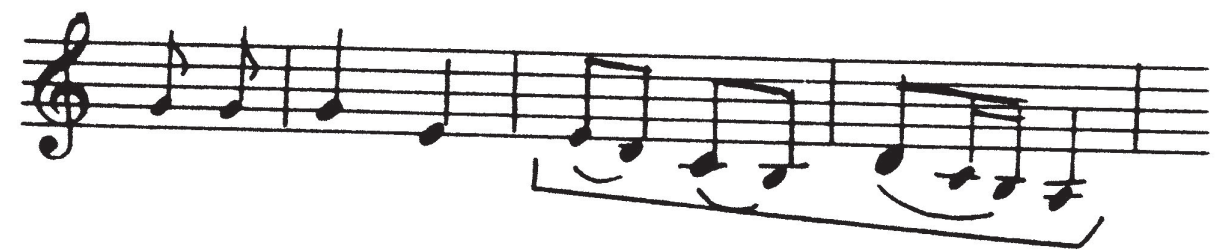

en el refrain

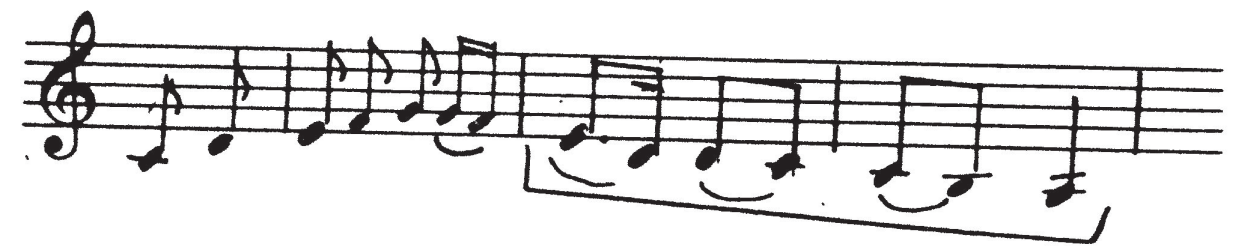

5 Sobre este "penúltimo» motivo, véase: Susana WЕICH-SHAHAK, «The Wedding Songs of the Bulgarian Sephardi Jews». Orbis Musicae, 7 (1980), 81-107, en pp. 102-104. 
De la tradición de los sefardíes de Occidente citaremos un ejemplo paralelo de canción de ajuar, grabado en Kiriath Malahi, en 1979, cantado por Rahma Lucasi, Elvira Alfasi, Fortuna Mesas y otras mujeres, todas ellas oriundas de Larache.

El texto de esta canción recalca el hecho de que el ajuar se expone para que la familia del novio «no tenga qué decir», ya que es fruto del arduo trabajo de la novia, quien ha cosido y bordado día y noche.

La música es viva, en compás binario, y la melodía tiene un diapasón de una octava, en escala mayor. La relación texto / música es mayormente silábica, con unas pocas ornamentaciones.

Es interesante señalar que, aun difiriendo notablemente en su melodía, las dos canciones de ajuar aquí presentadas tienen la misma estructura formal, respondiendo al esquema $a$ al $b \quad c \quad b \quad c$, y en ambas las frases al terminan en el tercer grado de la escala, las a continúan de ese tercer grado con un ornamento que lleva a la subtónica, y las frases $c$, finalizan en la tónica. Además en ambas canciones el compás es binario, ambas están en un modo mayor (con el cuarto grado elevado en un cuarto de tono, en la canción búlgara), presentando en el texto una alternación de versos largos y cortos.

\title{
Ejemplo $n^{\circ} 4$
}

\author{
Ajuare nuevo \\ delantre vo lo pondré, \\ suegrà y cuñada, \\ no tèngáis qué decir; \\ la nuestra novia \\ todò lo veló al candil.
}

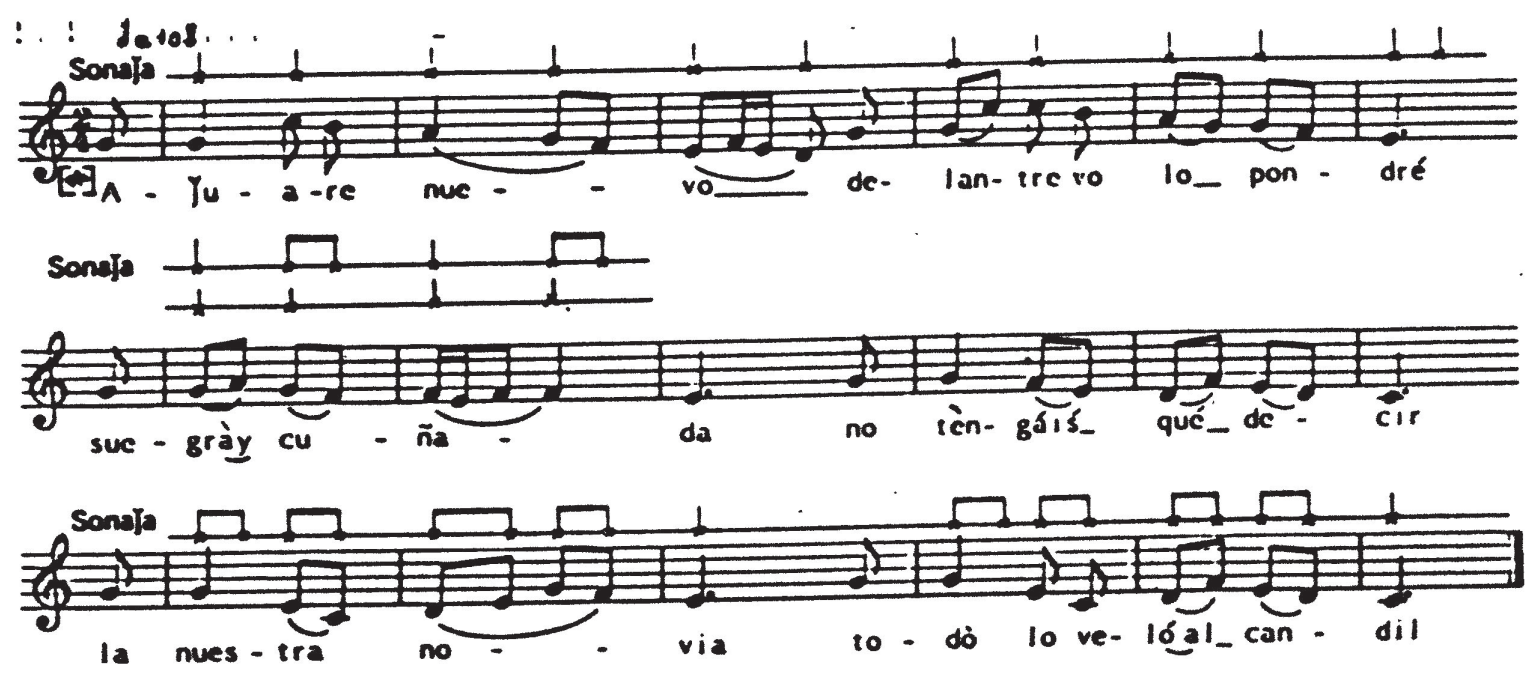


La segunda en la cadena de ceremonias que tomaremos como ejemplo, es el "baño de la novia», que festeja el baño ritual de la joven, generalmente un día antes de los esponsales. En esta ocasión la novia va acompañada por las mujeres de ambas familias. Ellas se encargan de lavarla, enjabonarla, secarla, vestirla y peinarla, considerándose cada una de estas tareas como un honor para la que es designada a cumplirla.

El ejemplo de Oriente fue grabado en Yaffo, en 1977, cantado por Rachel Levy, oriunda de Sofía.

El texto de la canción tiene tres estrofas, cada una de ellas de tres versos, los dos primeros de 8 ó 9 sílabas, mayormente en rima asonante (excepto en la primera estrofa) y el tercero, de 10 sílabas, repetido (idéntico o levemente variado) en las tres estrofas. Además, lleva un estribillo de dos versos octosilábicos rimados, el cual se repite después de cada estrofa. El contenido del texto refleja la descripción previa: la ida de la novia al baño ritual de la judería, el séquito que la acompaña y las monedas (ducados) arrojadas a su paso como augurio de prosperidad.

La música, en tempo reposado, tiene tiempos y acentos claros, en un compás estable de $2 / 4$. La melodía, en el modo de Mi (como en el maqam qurd) tiene una diapasón de una octava y se mueve por notas adyacentes, con pocos saltos interválicos.

\section{Ejemplo n. 5}

Cuando yo del baño salgo, del bañò de la judería, que vos acompa la compañía.

Voś vení con mi amor, amolor, cara de flor.

Cada paso, yo un ducado, onde el novio, a tres o a cuatro, que voś aspera la compañía. Vos vení con mi amor,
amolor, cara de flor.

Los ducadoś $m$ ' arronjates̀, en el còrazón me dates̀, que vos acompa la compañía.

Voś vení con mi amor, amolor, carà de flor.
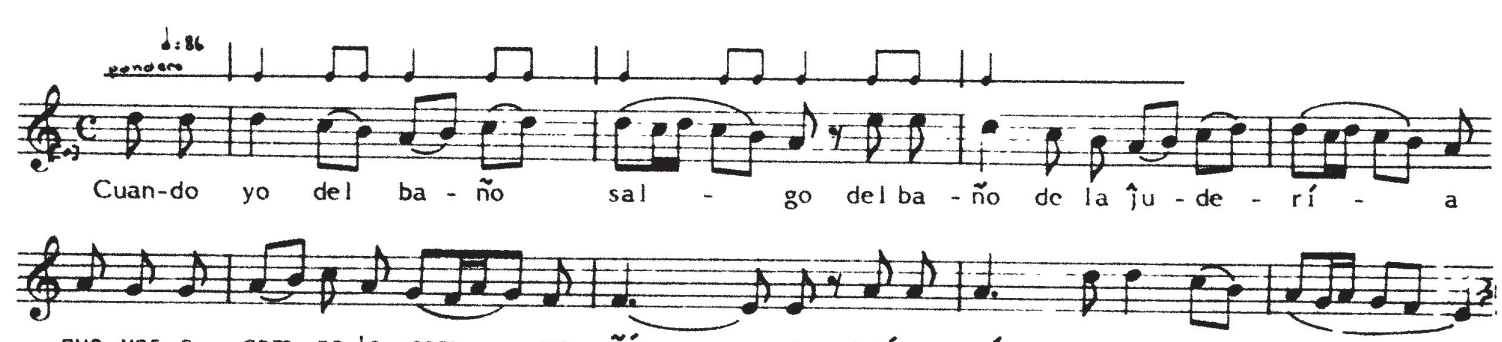

que vos a - com-pa la com - pa- ñi -

a voś ve - ní

con $\mathrm{mi}$
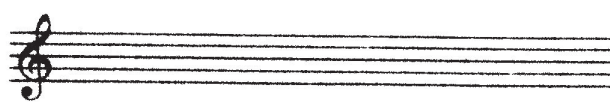

A - mo - lor ca 
El siguiente ejemplo es una canción marroquí para el baño de la novia. Ha sido grabado en Ashkelon en 1983, cantado por Alicia Bendayan de la ciudad de Tetuán.

El texto de esta canción tiene dos estrofas paralelas en su contenido y en su formulación. Cada estrofa tiene cuatro versos decasilábicos, con un "ay» agregado al principio de cada una de las dos estrofas, que hace al primer verso endecasilábico. Los versos van rimando en asonante de dos en dos, lo cual se refleja en la música, que, ignorando las dos estrofas definidas por su paralelismo semántico, presenta un período de dos frases que se repite, con pequeñas variaciones, para cada dos versos del texto. Es interesante notar que la primera de ambas frases termina en un sonido a una segunda mayor debajo de la finalis en que concluye la segunda frase. Este descenso antes de la última (en este caso la segunda) frase musical aparece en muchas canciones de la tradición oriental y de la occidental, como ya lo hemos señalado en el ejemplo $n .^{\circ} 3$.

La melodía se mueve por notas adyacentes, con muy pocos saltos (uno de ellos entre la nota final de un período y la primera del siguiente), en un tempo reposado con una base métrica de $3 / 8$ en varias combinaciones, como $9 / 8$ y 12/8. La canción está en modo menor, en el modo de $\mathrm{Re}$, en un diapasón de una séptima mayor.

\section{Ejemplo $n^{\circ} 6$}

Ay, que si te fueres a bañar, novia, llevà a tu madre y non vayas sola, para quitarte la tu camisa, para meterte en el agua fría.

Ay, que si te fueres a bañar, novia, llevà a tu suegra y non vayas sola, para sacarte del agua clara, para ponerte la tu delgada.

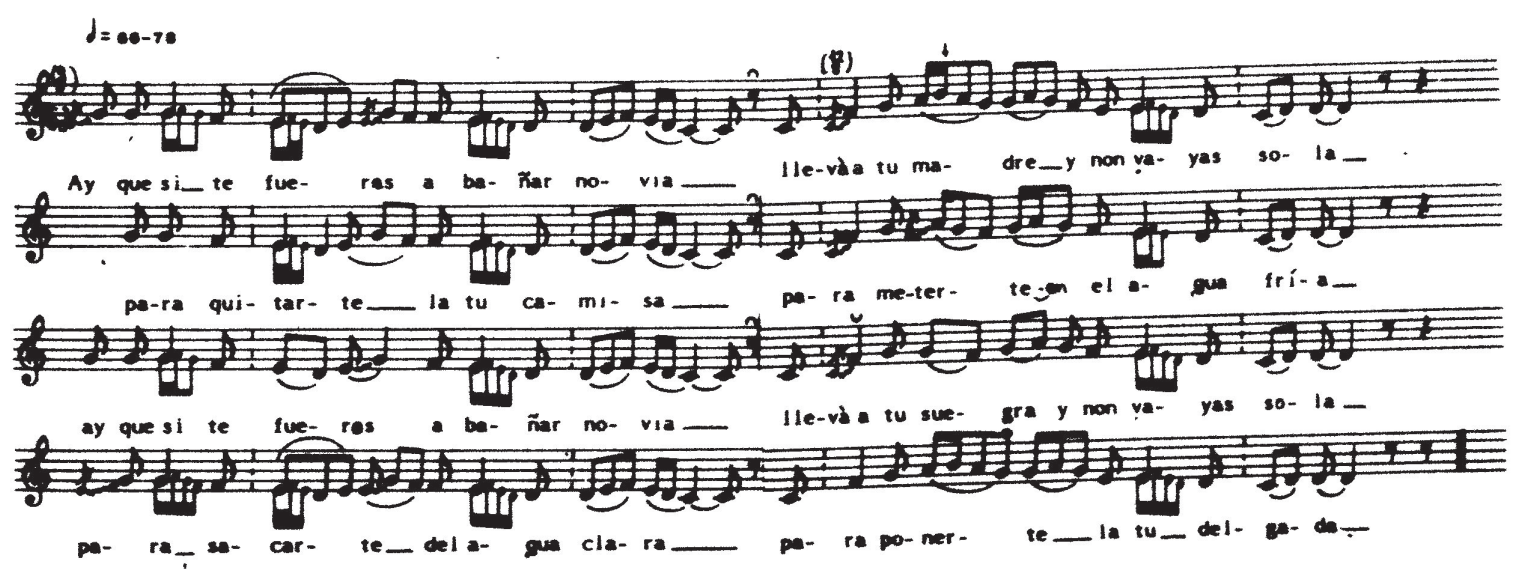


Sin atrevernos a adelantar ninguna hipótesis respecto a un origen común, anterior a la expulsión de España, podemos notar sin más, que ambos ejemplos de canciones para el baño de la novia (n. ${ }^{\circ} 5$ y 6) presentan, no obstante, sus diferencias en cuanto a tonalidad y organización rítmica, ciertas similitudes melódicas, que se señalan en la siguiente presentación paradigmática:
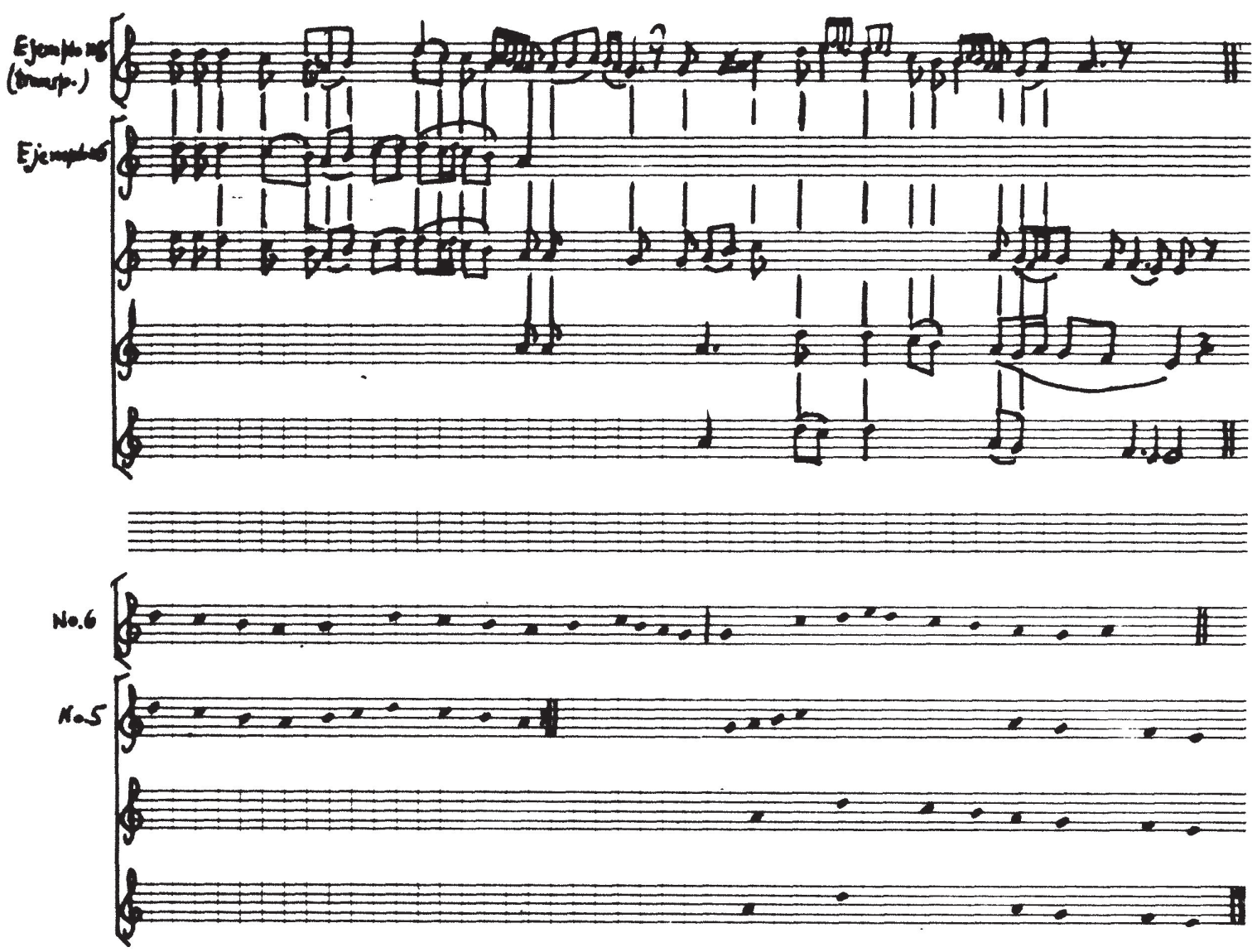

Los siguientes ejemplos están relacionados con el festín de boda. En este caso presentaré dos de la tradicional oriental y uno de la occidental, entre los cuales puede comprobarse una concordancia textual en varios de sus versos.

El primero de los ejemplos de Oriente fue grabado en Yaffo, en 1977, cantado por la ya mencionada Matilda (Mazal-tov) Lazar.

El texto de esta canción describe las mesas para la fiesta, con bendiciones de que nunca falte (mos manque) el pan y el vino, para la nueva pareja y para todos los convidados. Tiene dos estrofas de cinco versos cada una que difieren solamente en el primer verso, el cual se canta consecutivamente dos veces, con melodía variada en su comienzo: 

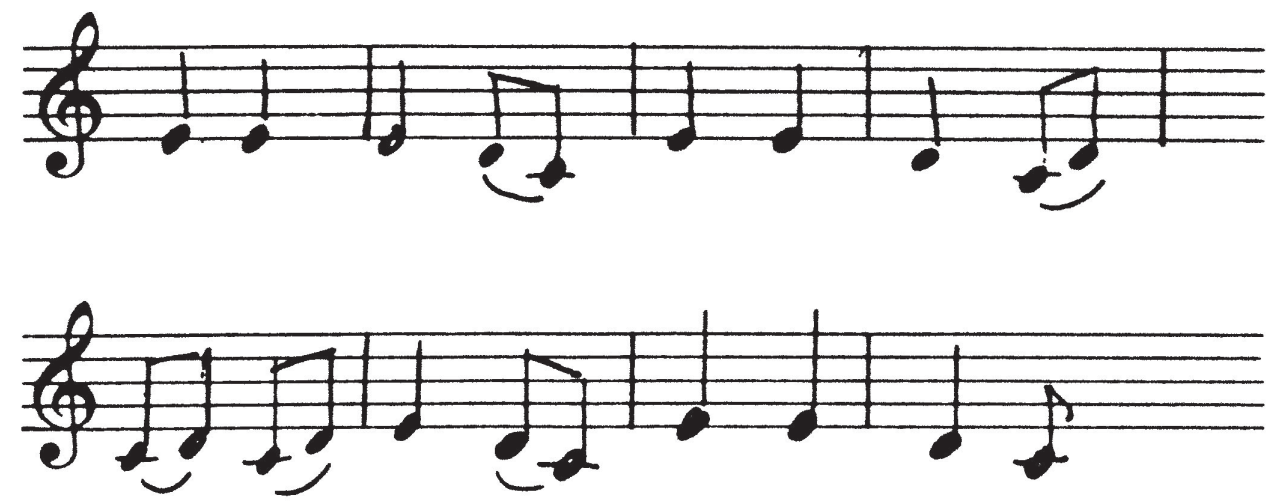

La repetición del primer verso en las canciones del ciclo vital parece ser muy común en la tradición balcánica ${ }^{6}$.

La música de este ejemplo tiene, consecuentemente, seis frases musicales en cada estrofa textual. El tempo es reposado, con división métrica en $2 / 4$. La melodía, predominantemente de marcha diatónica, en un ámbito de una séptima menor, está en un modo mayor, llegando a la finalis por descenso desde la segunda mayor superior.

También en esta canción podemos observar el descenso, por grados conjuntos, a una nota debajo de la finalis, como conclusión de la penúltima frase

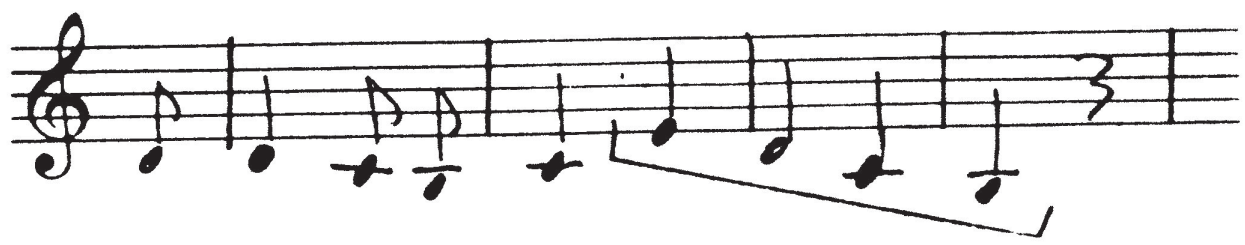

Además, el descenso a la tercera menor inferior a la finalis, poco antes del fin de la última frase

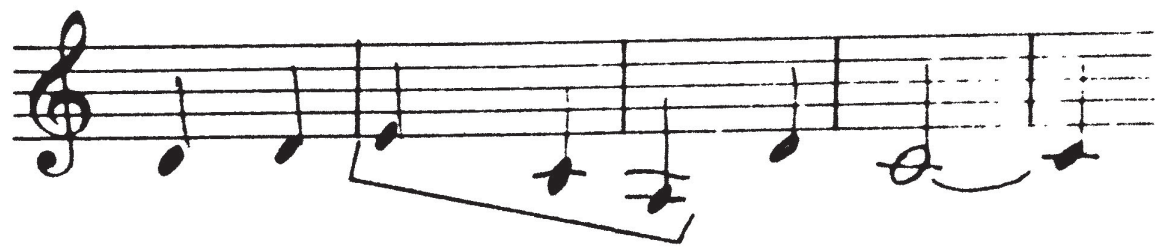

6 Ibid., p. 104. 


\section{Ejemplo n. 7}

Estas mesas son del vino,

que viva la patrona con su marido,

los que 'stán alderedor,

que gocen y logren de que son,

estas mesas, mesas son.

Nunca mos manque el pan ni el vino, viva la patrona con su marido, los que 'stán...

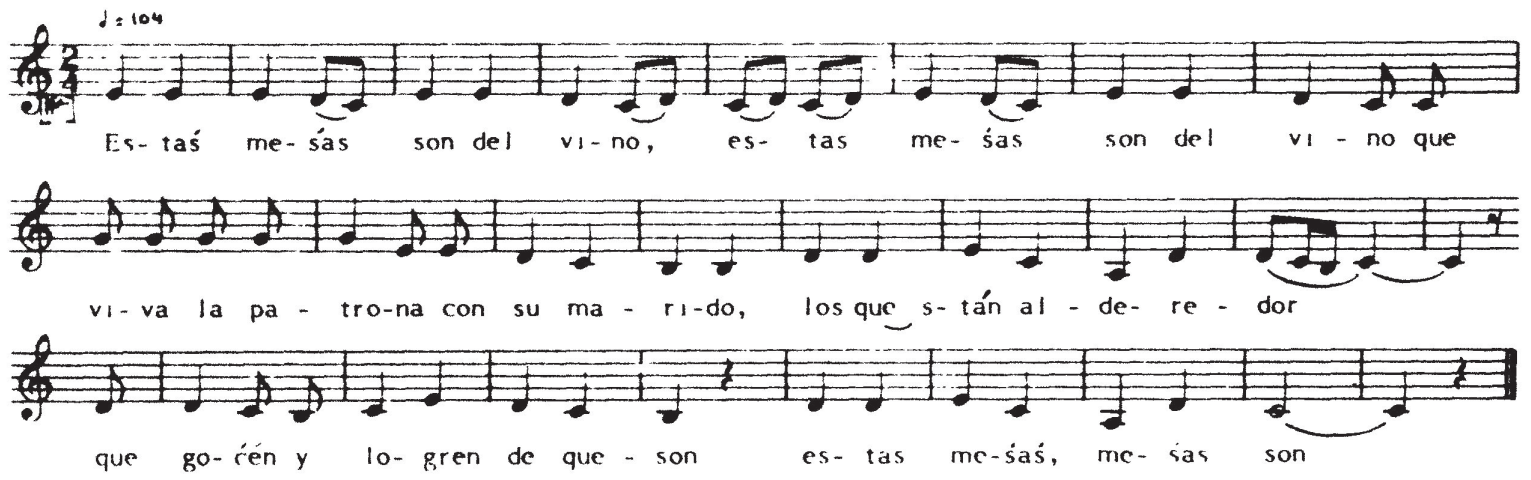

El segundo ejemplo de la tradición oriental fue grabado en Yaffo, en 1976, cantado por la ya mencionada Rachel Levy, de Sofía.

El contenido del texto se refiere a las casas donde se celebra la fiesta de la boda y al baile que tiene lugar en esa ocasión.

Tiene dos estrofas, cada una de tres versos: dos largos y uno corto (dos octosilábicos y uno tetrasilábico), con un estribillo de dos versos, uno largo (de 9 sílabas) y uno corto (de 4), finalizando con un tarareo.

Después de repetir, texto y música, el primer verso, la música enlaza los versos de las estrofas con el estribillo. A las seis frases de la música de las estrofas, el tarareo agrega cuatro segmentos musicales, de los cuales los tres primeros son idénticos y sólo el último, de distinta melodía, provee una conclusión sobre la tónica.

La melodía está en modo de La (menor), con más saltos interválicos que los ejemplos anteriores, en un ámbito de una octava. La nota inferior, una segunda mayor debajo de la finalis, aparece terminando un descenso diatónico en la penúltima frase de cada estrofa, así como en la penúltima del estribillo y, como primera nota, acentuada, en cada uno de los primeros tres segmentos o compases del tarareo. 


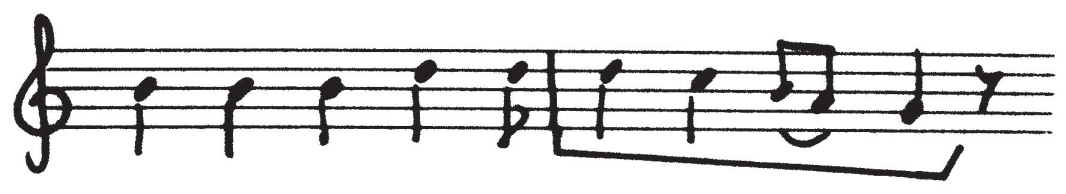

El ritmo de esta canción, en tempo vivo, evidencia la influencia de la tradición musical balcánica sobre la de los judíos sefardíes de Bulgaria, presentando una división métrica de $9 / 8$, que resulta de la combinación de $3 / 4+3 / 8$. Este metro se acentúa en el acompañamiento del pandero, que ejecuta un esquema en el cual se omite la última corchea:

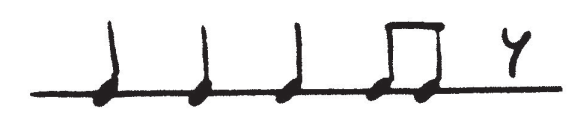

Ejemplo n. ${ }^{\circ} 8$

Oy, qué caśas tan hermosas, para que bailen las novias para bodas, para bodas, las mis siñoras, ésta y otra.

La lara la la...
Afuera bailan las damas, arientro bailan galanas, para bodas, para bodas, las mis siñoras, ésta y otra. La lara la la...
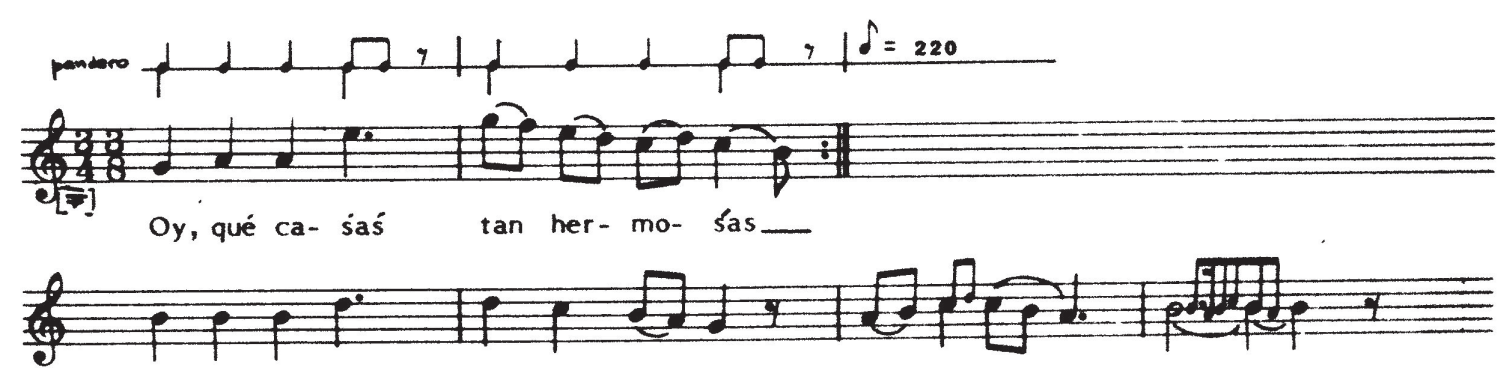
pa-ra-que bai - len laś no-viaś pa- ra bo - - daś

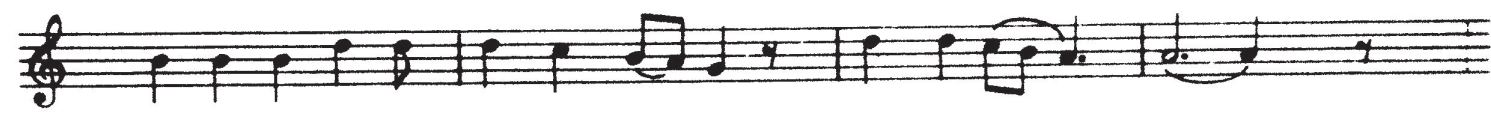
pa-ra bo-daś las mis si-ño-raś és-tayo - tra

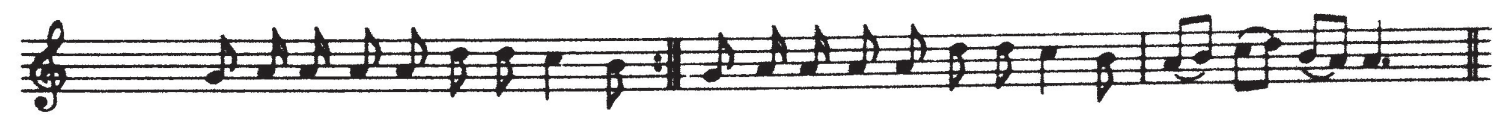

La la ra la la la la la la la la ra la la la la la la la la la la

El siguiente ejemplo pertenece a la tradición marroquí y fue grabado en Ashkelon en 1984, cantado por Alicia Bendayán, de Tetuán.

El texto presenta once estrofas, cada una de dos versos asonantados, cuyo número de sílabas por verso varía desde 8 a 13 , frecuentemente 
con acentos inesperados en la última sílaba («caballerò, dedò, manò», etc.), ligados probablemente a la estructura musical.

Hay unidad temática y paralelismo en la formulación de grupos de estrofas: las dos primeras, referidas a las casas para la boda, la quinta y la sexta, a la preparación del ajuar, las séptima, octava y novena, al anillo de boda. La tercera estrofa tiene su paralelo temático en la canción del ejemplo anterior ( $\left.\mathrm{n}^{\circ} 8\right)$, mientras que la cuarta se asemeja al $n .^{\circ}$ 7.

La música es de tempo reposado y compás binario (4/4). La melodía se mueve por grados conjuntos en un ámbito de una sexta mayor, en modo de $\mathrm{Fa}$, con el tercer grado ocasionalmente bemol, formando una escala del tipo del maqam hidjaz.

Ejemplo $n .^{\circ} 9$

$Y$ estas casà altas son, para bodas buenas son.

$Y$ estas casas son de pino, en ellas mora un hombre rico.

Nunca le falte el pan ni el vino, ni a la novia su marido.

Esta palomita, hermano Atál, cómo la puditis enamorar?

Como vo la diera su señor padrè andando y añadiendo en los ajuares.
Y aunque le dí la mano al caballerò, ànillito de oro puso en mi dedò.

Aunque le dí la mano, la mano le dí, y aunque le dí la mano y no $m$ 'arrepentí.

Y aunque le dí la mano al hijo de Albó, ànillito de oro puso en mi manò.

Y un amor que yo teníà, manzanitas de oro él traíà.

Cuatro y cinco en una encinà, la más bonita de ellas para mi amigà.

Como vo la dieran los sus hermanos, andando y añadiendo en los ducuados.

El último par de ejemplos representa a las canciones relacionadas con la transición final del hombre: la muerte. las canciones de duelo, llamadas endechas u oinas, eran entonadas, hasta tiempos no lejanos, por mujeres especializadas que se denominaban, por tal ocupación, endechaderas u oinaderas. Hoy es difícil recoger endechas por la reticencia de las informantes ante un tema luctuoso cuya ejecución atraiga el pesar ${ }^{7}$.

7 Las endechas constituyen, dentro del repertorio sefardí, uno de los géneros en peligro de desaparición en la tradición oral, ya que, a diferencia de otros géneros funcionales que trocaron su ocasionalidad básica por la de canciones que se ejecutan hoy 

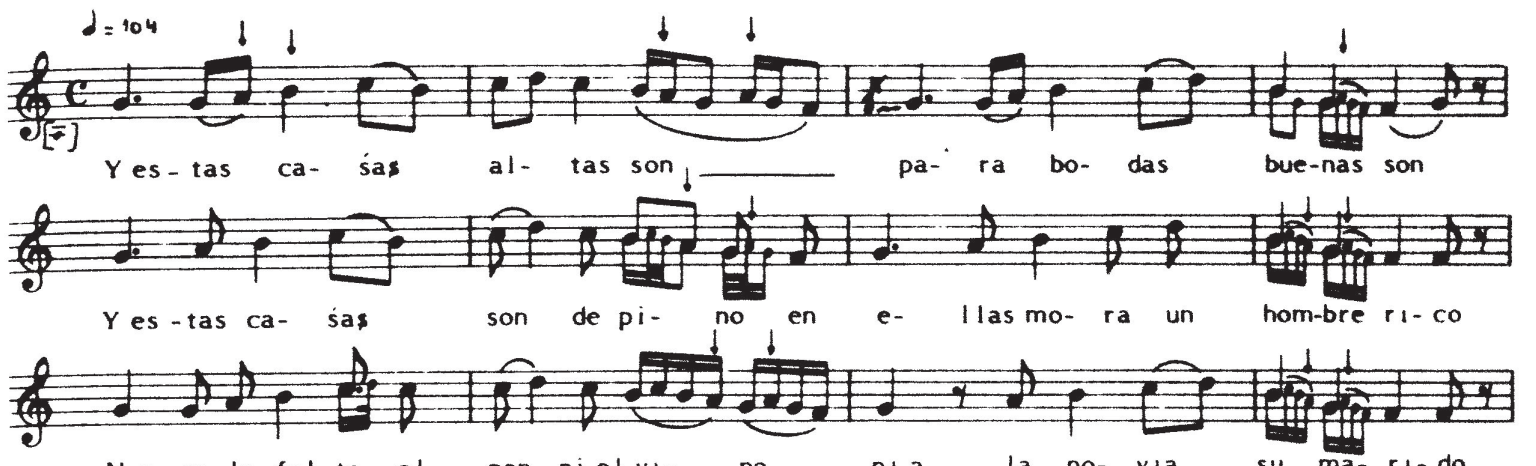
Nun-ca le fal-te el pan nielvij no nia la no- via su ma-ri-do
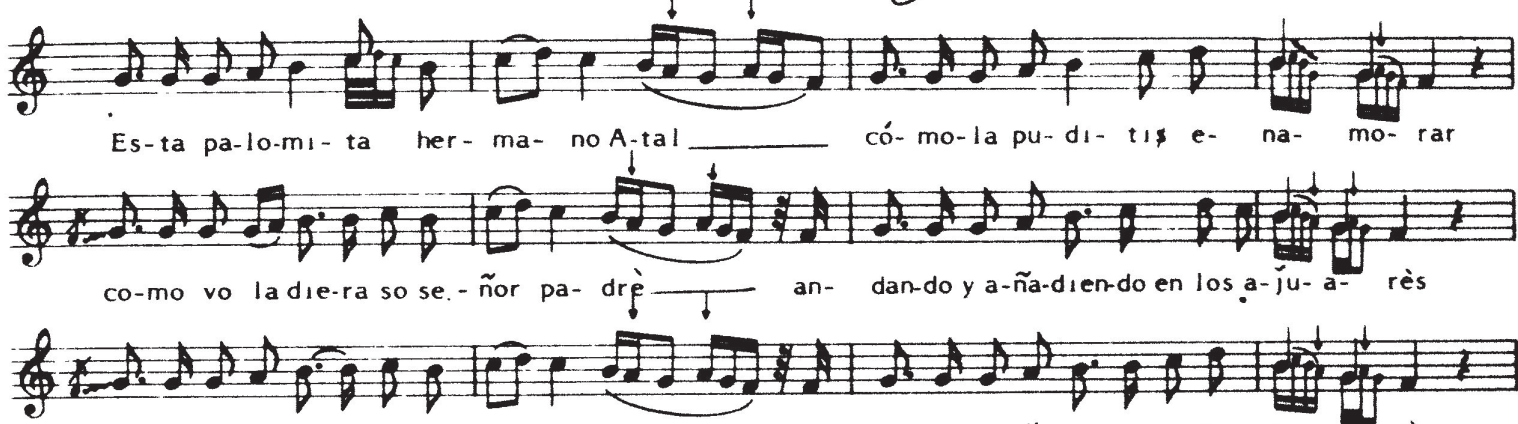

co-mo vo ladie-ran susher-ma-nos an-dan-do y a-ña-dıen-do en los du- cua-dds

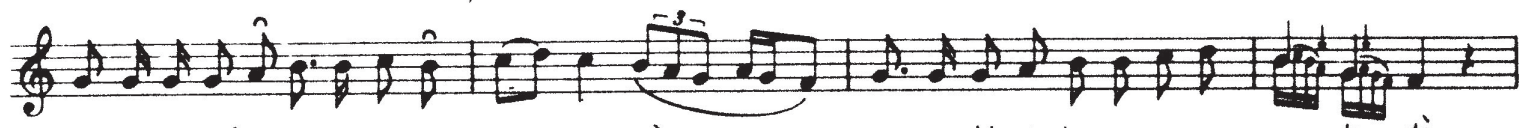
Yaun que le dí la ma-no al ca- ba- lle-rò_ a- ni-lll-tode o-ropu-so en mi de- dó Aun que le dí la ma-no la ma- no le dílo yeun-que le di la ma-no no me a- rre-pen-

El primer ejemplo es de la tradición oriental, grabado en Yaffo, en 1976, cantado por Matilda (Mazal-tov) Lazar.

El texto de la versión aquí presentada tiene tres estrofas que son cuartetas con versos de longitud variada (entre 6 y 9 por verso) y de rima inconsistente, tal vez porque originariamente habría improvisación en el texto. El tema es la despedida de una madre agonizante.

La música es estrófica, de acuerdo al texto, cada estrofa musical con cuatro frases de igual duración. El tempo es calmo, en compás binario $(2 / 4)$, con una melodía que se mueve por grados conjuntos en un ámbito de una sexta mayor y con una escala menor, en modo de Re, con el segundo grado disminuido en un cuarto de tono (formando dos intervalos consecutivos, entre el primero, segundo y tercer grado, de $3 / 4$

en reuniones sociales, como cantos alegres de grupo, las endechas, por sus lúgubres asociaciones, no han tenido tal suerte. Solamente se ejecutan hoy día las endechas entre las canciones luctuosas (qinot) que se cantan en el día de la conmemoración de la destrucción del Templo, en el 9 del mes de $A v$. 
de tono) como en el maqam bayat. Podemos observar nuevamente en este ejemplo el descenso diatónico a la subfinalis (Do) al final de la penúltima frase.

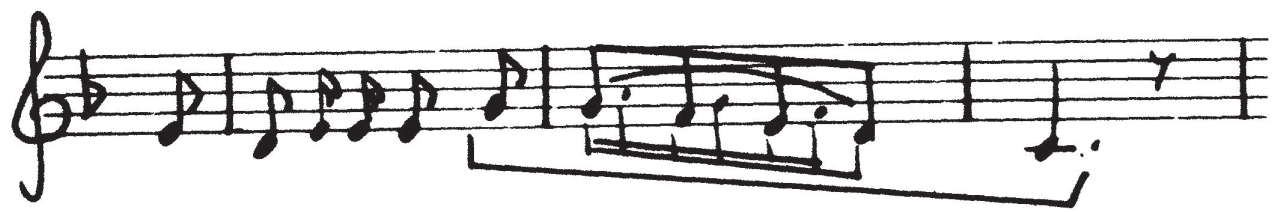

Ejemplo n. ${ }^{\circ} 10$

A poco lloralda, a muncho bušcalda, que más ya no la vas̀ a ver, se está yendo al otro mundo.

Vinid miś hijicoś, al bib de la cabecera, verés cuando me muero, me s' arranca ' 1 alma.

A poco llorame, a muncho bušcame, que más madre no tenés, ya se está pedriendo.

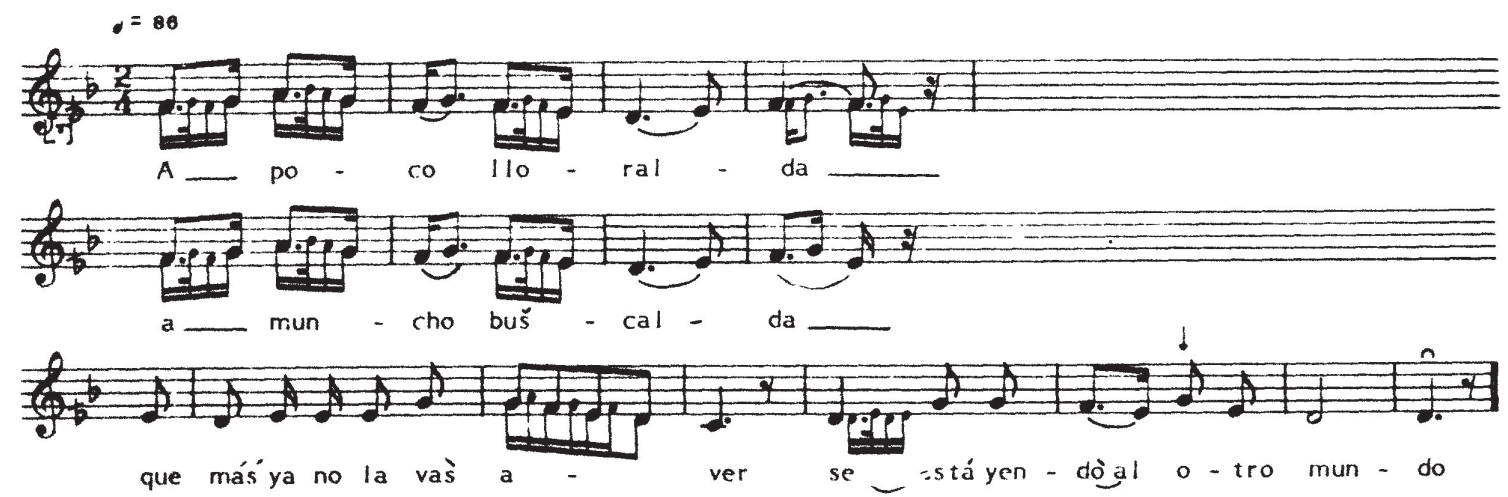

Nuestro último ejemplo es una endecha de Marruecos, grabada en Ashdod en 1979 y cantada por Flora Bengio, oriunda de Tetuán.

El texto presenta seis cuartetas hexasilábicas (salvo pocas desviaciones) rimando inconsistentemente los versos pares. Su contenido, a diferencia de la endecha anterior, no se refiere, ni siquiera alude, al tema de la muerte, sino que se centra en el de la desesperación y el triste destino. 
Hay paralelismo en las dos primeras estrofas, que en realidad sólo difieren en las últimas palabras de los versos pares ${ }^{8}$.

La música es, en correspondencia, estrófica, con una sola estrofa musical que se repite, con ínfima variación, a lo largo del texto. El ritmo es claro, en un compás de 6/4 (o en grupos de tres compases de 2/4). La melodía es hexatónica, en modo de $\mathrm{Mi}$ en un ámbito de una séptima menor, donde la subfinalis aparece una sola vez cerca del fin de la estrofa musical y el quinto grado (Si) se omite.

Cada estrofa musical tiene cuatro frases de igual duración, de seis tiempos cada una, comenzando casi cada frase con anacrusis.

\section{Ejemplo n. ${ }^{\circ} 11$}

Ya crecen las hierbàs

y dan de color,

y éstè, mi corazón,

vive con dolor.

Ya crecen las hierbàs

y dan de amarillò

y éstè, mi corazón,

vive de suspirò.

Parióme mi madrè

en noche oscurà,

ni gallo cantabà

ni perro ladrabà.
Sólo la aguilillà

negras voce dabà;

parióme mi madrè

crióme mi tíà.

Púsòme por nombrè:

niña sin fortunà;

parióme mi madrè

y echóme en la cunà.

Con hierbas del campò

$m$ ' hiźo cama y cunà,

púsòme por nombrè:

niña y sin fortunà.
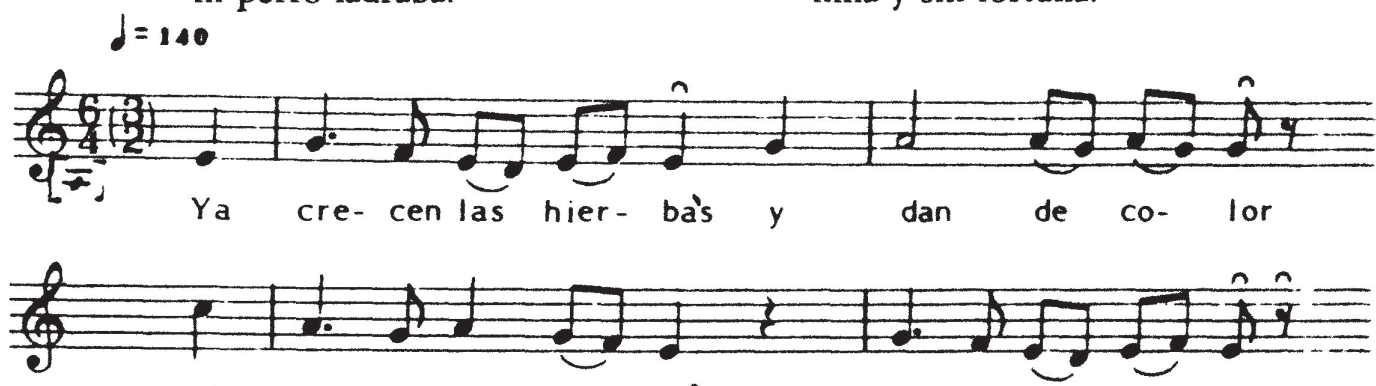

yes- tè mi co- ra- zón vi-ve con do- lor
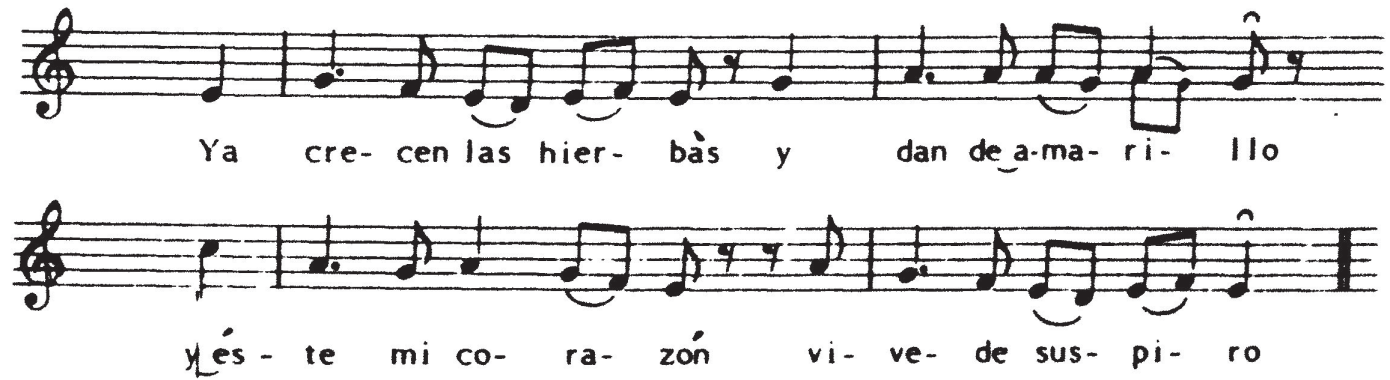

8 En las dos primeras estrofas el mencionado hexasilabismo se altera, en los terceros versos de ambas estrofas, por el agregado de keste». 


\section{CONCLUSIÓN}

Los ejemplos aquí mencionados han sido seleccionados casi al azar dentro del repertorio del cual forman parte, frecuentemente escogidos entre otras canciones del mismo tema y ocasionalidad. Pese a lo casual de su elección o, si se quiere, precisamente por ello, podemos apreciar en esta colección la riqueza y variedad del repertorio sefardí relativo al ciclo vital, tanto en lo referente a su estructura textual como a la musical.

Respecto a los textos podemos decir que en este repertorio - a diferencia de otros géneros como los romances y las coplas festivas- se utiliza un lenguaje coloquial común a la lengua hablada a diario.

En la temática de las canciones hemos señalado las alusiones claras a los usos y costumbres que acompañan a las ceremonias, revelando no poco de la concepción existencial de las comunidades sefardíes.

En su estructura textual la variedad se evidencia en los distintos esquemas métricos de las canciones (dísticos, tercetos, cuartetas, etc.), la volubilidad de la rima y el ocasional empleo de paralelismo.

Decididamente, este aspecto textual del repertorio deberá ser estudiado a fondo por investigadores que se ocupen precisamente de los análisis literarios de las canciones.

Intentaremos, en cambio, resumir, a partir de los ejemplos presentados, las características musicales de este repertorio:

1. En el parámetro de la estructura formal vemos representados distintos tipos:

1.1. Canciones cuya música comprende una sola entidad formal, de una o dos frases musicales, como una letanía que se repite, con mayor o menor variación, a lo largo del texto (n. ${ }^{\text {os }} 2,6$ y 9 ).

1.2. Canciones de estructura estrófica con una unidad musical de variado número de frases, que se repite, con mayor o menor variación, para las distintas estrofas del texto ( . $^{\text {os }} 4,10$ y 11 ).

1.3. Canciones con dos unidades musicales, estrofa y estribillo, que sustentan textos de estructura paralela (n. ${ }^{\text {os }} 3,5,7$ y 8 ).

1.4. Canciones de estructura estrófica, con una primera estrofa musical distinta (en melodía y ritmo) de todas las estrofas restantes $\left(n .^{\circ} 1\right)$.

2. En el parámetro del ritmo hemos visto que el tempo es mayormente calmo, excepto en las canciones de boda, donde es más vivo. Respecto a la organización métrica, hay en nuestros ejemplos canciones de diversos tipos:

2.1. Canciones sin estructura métrica, es decir, sin periodicidad en los acentos (n. $\left.{ }^{0} 2\right)$. 
2.2. Canciones con acentos periódicos que definen metros binarios, en compás de $2 / 4$ o de $4 / 4$ (n. ${ }^{\circ s} 3,4,5,7,9$ y 10$)$.

2.3. Canciones en metro ternario $\left(\mathbf{n}^{\circ} 11\right)$.

2.4. Canciones en metros compuestos, como $3 / 4+3 / 8\left(n^{\circ} 8\right)$ ó $9 / 8$ y $12 / 8\left(n^{\circ}{ }^{\circ} 6\right)$.

2.5. Canciones con una primera estrofa en compás distinto del de las otras estrofas $\left(\mathrm{n}^{\circ} 1\right)$.

3. En el aspecto melódico hemos señalado que las tonadas de las canciones presentadas se mueven generalmente por grados conjuntos, con muy pocos saltos. Los ocasionales intervalos mayores ocurren entre la última nota de una frase y la primera de la siguiente y menos frecuentemente dentro de una frase de la canción.

Ornamentaciones melódicas aparecen también en nuestros ejemplos, si bien debemos hacer constar que en el repertorio del cual nos ocupamos, los melismas son menos frecuentes que en otros géneros (tales como los romances y las coplas festivas).

La relación entre música y texto es generalmente silábica en estas canciones del ciclo vital, debiendo también señalar que se dan, a veces, acentos inesperados, ligados a la adaptación del texto a las tonadas de las canciones.

Las escalas en estas canciones son variadas, incluyendo escalas mayores (n. ${ }^{\circ s} 2,4$ y 7), modales ( $.^{\circ s} 1,5,6,8$ y 11) y maqamáticas ( $.^{\circ s} 3,9$ y 10$)$.

Las melodías se mueven en ámbitos bastante estables, oscilando entre una sexta mayor y una octava. A la nota final llega la melodía generalmente por descenso (en nueve de los ejemplos).

En varias canciones $\left(n^{\text {os }} 3,6,7,8\right.$ y 10 ) hemos podido observar el descenso, frecuentemente diatónico, a la subfinalis o a una nota inferior (una tercera menor por debajo de la finalis) que ocurre al terminar la penúltima frase y/o en un tiempo acentuado cerca del final, como anunciando el término de la estructura musical.

Como ya se ha dicho antes, la intención del presente artículo es solamente atestiguar la existencia del repertorio, ligado al ciclo de la vida. Por lo tanto, más que llegar a definiciones estilísticas, pretendemos aquí tan sólo presentar el repertorio, que únicamente la publicación de antologías exhaustivas podrán mostrar en toda su riqueza y variedad.

SUSANA WEICH-SHAHAK

Jewish Music Research Centre Hebrew University Jerusalem 
En el rico repertorio musical, cantado en Judeo-español y preservado en la tradición oral de los judíos sefardíes, numerosas canciones están relacionadas con las ceremonias que acompañan a los ritos de tránsito que marcan el ciclo de la vida humana: nacimiento, matrimonio y muerte. El presente artículo estudia y compara varios ejemplos, seleccionados de este repertorio funcional de los judíos sefardíes del Oriente y el Occidente del Mediterráneo, recogido en encuestas en Israel, de inmigrantes de ambas zonas. Se incluyen transcripciones y análisis de música y texto de los ejemplos, y se señala la funcionalidad de estas canciones en las comunidades sefardíes.

In the rich musical repertoire, sung in Judeo Spanish, and preserved in oral tradition by the Sephardic Jews, numerous songs are related to the ceremonies that accompany the passage rites which define stages of the life-cycle: birth, marriage, and death. This article studies and compares several examples, selected from this functional repertoire of the Sephardic Jews (from both, the East and West Mediterranean areas), which were collected by the author, in Israel. Musical and textual transcriptions and analisis of the examples are provided, stressing the functionality of these song in the life cycle of the Sephardic Communities. 